\title{
Morbidity and mortality of endoscopist-directed nurse-administered propofol sedation (EDNAPS) in a tertiary referral center
}

Authors

Institution
Marie Ooi, Andrew Thomson

The Canberra Hospital, Gastroenterology Unit, Canberra, Australian Capital Territory 2600, Australia
Bibliography

DOI http://dx.doi.org/

$10.1055 / \mathrm{s}-0034-1392511$

Published online: 11.8.2015

Endoscopy International Open

2015; 03: E393-E397

(c) Georg Thieme Verlag KG

Stuttgart $\cdot$ New York

E-ISSN 2196-9736

\section{Corresponding author}

Andrew Thomson

The Canberra Hospital

Gastroenterology Unit

PO Box 11

Woden

Canberra

Australian Capital Territory 2600

Australia

Fax: 62347922

Andrew.Thomson@act.gov.au
Background and study aims: Endoscopist-Directed Nurse-Administered Propofol Sedation (EDNAPS) has been evaluated in community settings rather than tertiary referral centers.

Patients and methods: A hospital-wide prospectively collected database of Medical Emergency Team Calls (METCALL), emergency responses triggered by medically unstable patients, was reviewed. Responses that followed EDNAPS were extracted and compared with a prospectively entered database of all endoscopies performed using EDNAPS over the same period.

Results: A total of 33,539 endoscopic procedures (16,393 gastroscopies, 17,146 colonoscopies) were performed on 27,989 patients using EDNAPS. Intravenous drugs included midazolam (0-5 mg), fentanyl $(0-100 \mathrm{mcg})$, and propofol (10-420 mg). Of 23 METCALLs (18 gastroscopies and 5 colonoscopies), there were 16 with ASA scores of III or higher. Indications for gastroscopy

\section{Introduction}

\section{$\nabla$}

The use of endoscopist-directed nurse-administered propofol sedation (EDNAPS) remains controversial because of concerns related to its safety, despite minimal evidence of improvement in safety with the use of anesthetic assisted sedation[1 -42]. In Australia, propofol is generally administered by specialist anesthetists [1]. Since 2000, Canberra Hospital, a major teaching hospital of the Australian National University Medical School, in Australia's largest inland city and capital, has used EDNAPS for most endoscopic procedures [2]. Despite accumulated evidence in regard to the safety of EDNAPS for routine endoscopic procedures, very few major teaching hospitals in Australia have adopted EDNAPS even for low-risk patients. In addition, EDNAPS is not used in many other western countries. EDNAPS provides the advantage of significantly reducing the cost of the endoscopic procedure without adversely af- were gastrointestinal (GI) hemorrhage $(\mathrm{n}=11 ; 8$ variceal, 3 nonvariceal), dysphagia $(n=5)$, PEG removal $(n=1)$, and dyspepsia $(n=1)$. Fifteen of 22 patients, including all of those who had a colonoscopy, made a full recovery and returned to the ward or were discharged home. In the gastroscopy group, seven were intubated and admitted to Intensive Care, of whom six were emergency cases for gastrointestinal bleeding ( $\mathrm{n}=4$ variceal, $\mathrm{n}=2$ non variceal) and one in which the indication was PEG removal. Two deaths occurred in the intubated group.

Conclusions: In a tertiary referral center, EDNAPS for low-to-moderate risk (ASA $\leq 2$ ) patients undergoing gastroscopy and colonoscopy is very safe. Gastroscopy is associated with greater anesthetic risk than colonoscopy and those with high ASA scores needing urgent endoscopy for upper gastrointestinal hemorrhage are at particular risk of cardiorespiratory decompensation.

fecting a patient's clinical outcome [3]. To date, the use of propofol sedation has mainly been assessed in the community setting rather than in a tertiary referral center [3]. This article analyses the safety of the use of EDNAPS for endoscopic procedures in a tertiary referral center.

\section{Patients and methods \\ $\nabla$}

Between January 2004 and November 2012 at our institution, reports for all endoscopic procedures performed in the endoscopy unit were generated using a standardized reporting system, in which key parameters such as indication, results, interventions, and conclusion were mandated. A program of quality assurance with mandatory reporting of unplanned events, which were reviewed at unit meetings every 6 weeks, was also ongoing. In addition, over the study period, details of all Medical Emergency Team (MET) calls 
at the hospital were collected by a dedicated group of physicians and nursing personnel and entered contemporaneously into an excel database. Importantly, MET calls (criteria listed below) can be activated any time, 24 hours a day, 7 days per week. MET calls that occurred between January 2004 and November 2012 were analysed and those originating in the endoscopy suite were reviewed.

The MET team consists of five to six people (two or three doctors - one from the emergency department, one from internal medicine and, if available a doctor from the anesthesia department - two wardsmen, and one senior nurse). Two back-up teams - one based in the emergency department and the other in the intensive care unit - attend MET calls if the "primary" MET team is already involved in such a call. Events at each MET call are recorded contemporaneously and data are reviewed weekly. Data related to patients receiving MET calls following EDNAPS were examined. Further data with respect to those calls were obtained from the patients' medical records. The following parameters were noted: patient demographics and clinical characteristics, American Society of Anesthesiologists (ASA) score, procedure indication, clinical outcomes of the MET calls, need for mask ventilation, need for endotracheal intubations, and death. These data were then compared with prospectively entered information from all upper gastrointestinal endoscopies and colonoscopies performed using EDNAPS in the endoscopy unit over the same study period (Jan 2004-Nov 2012). Because of a failure to record in the computerized database whether procedures were done on an emergency basis, handwritten records were examined to determine the number of such procedures during the study period. For any patient who enters one of the two endoscopy rooms in the endoscopy suite where all EDNAPS procedures are performed, it was (and continues to be) our practice to record details in hard cover notebooks contemporaneously and to place heavy ink markings around patient labels of cases done as emergencies. We were able to obtain relevant records for 43 of the 95 months of the study period, which gave us the number of emergency procedures performed using EDNAPS over the period from October 2004 until April 2008. To calculate the total number of emergency procedures over the study period on a pro rata basis, we multiplied the number for the 43-month period by the total number of months of the study (95) and divided by 43 . Similarly, the number of percutaneous endoscopic gastrostomy (PEG) tube placements during the study period was determined by examining a contemporaneously recorded list of PEG placements. This nurse-initiated record of PEG tube placements was developed many years before the study period to facilitate ready access to information regarding such patients on their return for revision or replacement of their feeding tubes, and thus, is highly comprehensive and accurate.

Procedures in which propofol had been administered by a specialist anesthetist, including all endoscopic retrograde cholangiopancreatography (ERCP) procedures, were excluded from the analysis.

\section{Nurse sedationist prerequisites}

The following requirements must be fulfilled before a registered nurse (RN) is permitted to administer propofol in the endoscopy unit:

- Registration as a RN with the Australian Health Practitioner Regulation Agency since 2012 and prior to that in the Australian Capital Territory Nurses Board;
- Annual written and practical assessment, conducted by a senior RN with experience in EDNAPS, for which a $100 \%$ score is required;

- Annual hands-on supervised administration of propofol observed by a senior staff member;

- Annual session with an anesthetist in the operating room in regard to advanced and basic life support, including airway maintenance (endotracheal intubation and laryngeal mask airway);

- Annual accreditation by the Department of Anesthesia;

- Provision of propofol sedation for at least 250 procedures/year in order to maintain accreditation; and

- Participation in the quality assurance program of the endoscopy center.

\section{Patient selection}

Patient selection criteria evolved over the duration of the study. The current exclusion criteria for EDNAPS are as follows:

- Age $<18$ years, body mass index $>35$ or weight $>120 \mathrm{~kg}$;

- Allergy to propofol (allergy to eggs or soybean);

- Prior complications with anesthesia;

- Difficult intubation/airway management (e.g., facial deformity) or potential risk of aspiration of gastric content;

- Significant cardiopulmonary disease;

- Obstructive sleep apnea requiring continuous positive airway pressure or bi-level positive airway pressure;

- Recent cerebrovascular disease or ischemic heart disease event or acute myocardial infarction; and

- Significant mental health issues.

\section{Sedation regimen}

Details of the sedation regimen have been published before [2]. All patients receive supplemental oxygen. Most fit adult patients receive a combination of low-dose short-acting opioid or benzodiazepines or both followed by boluses of propofol. An initial dose of 0 to $5 \mathrm{mg}$ of intravenous (IV) midazolam and 0 to $100 \mathrm{mi}-$ crograms IV fentanyl is usually given. The first dose of propofol $(10-30 \mathrm{mg})$ is then injected and titrated subsequently with boluses of 10 to $30 \mathrm{mg}$ of propofol at up to 1-minute intervals with the aim of inducing a level of sedation whereby patients are able to maintain their own airway without assistance and still able to respond to repeated tactile and noxious stimuli while remaining comfortable. The maximum propofol dose in our EDNAPS cohort was $420 \mathrm{mg}$. Once propofol is administered, no further opioid or benzodiazepine administration is permitted.

\section{Patient monitoring and post-procedural care}

All patients receive ongoing supplemental oxygen during and after the procedure. Automated pulse oximetry is used in all patients, with noninvasive monitoring of blood pressure at 3-minute intervals and continuous heart rate monitoring. This is continued in the recovery area until the patient is alert. Systematic telephone calls were made 24 hours after each procedure as part of follow up.

\section{MET Call Criteria}

A MET Call can be triggered by any staff member who is concerned about a patient and trigger criteria deliberately kept broad. Even if there are general concerns without a specific reason, a MET Call can be activated. The criteria for a MET Call are:

- Threatened airway

- Respiratory or cardiac arrest 
- Respiratory rate of $<5$ or $>36$ breaths per minute

- Oxygen desaturation $<90 \%$

- Systolic blood pressure $<90 \mathrm{mmHg}$

- Heart Rate $<40$ or $>140$ beats per minute

- Decreased level of consciousness

- Drop in Glasgow Coma Score by 2

- Seizures

The alteration in conscious state and Glasgow Coma Score did not lead to a MET call in the endoscopy unit if these changes were attributable to recently administered sedative medication.

Physiological derangements of a minor and transient nature did not trigger a MET call but were handled by the attending registered nurse. For instance, patients experiencing obstructed breathing were managed by "chin lift" in which the mandible is pushed forward by the attending nurse. Minor events of this nature were not systematically recorded.

\section{Results}

\section{$\nabla$}

We identified 27989 patients (mean age 57) who underwent 33539 endoscopic procedures (16393 upper endoscopies and 17146 colonoscopies) using EDNAPS. No endoscopic surgical dissections, endoscopic ultrasound examinations, or small bowel enteroscopies were performed under EDNAPs. The number of endoscopic mucosal resections (for Barrett's esophagus or for laterally spreading colonic lesions) was not systematically recorded. However, the total number of these procedures was very small certainly fewer than $0.2 \%$ of the total number of procedures. The numbers of percutaneous endoscopic gastrostomy (PEG) tube placements and emergency procedures were also not systematically recorded in the computerized database. During the EDNAPS study period, 118 PEG gastrostomy tubes were inserted. Over the 43 months from October 2004 to April 2008, 180 emergency procedures were performed using EDNAPS. The estimated total number of emergency procedures over the study period was calculated to be 398 ( $180 \times 95 / 43)$.There were no esophageal, duodenal, or colonic stent placements in the series nor were there any cystogastrostomies for pancreatic pseudocysts.

Over the 9-year period, there were 23 MET call cases, 18 related to upper endoscopies and five in patients who had undergone colonoscopies. The demographic details and clinical course of the patients receiving MET Calls are outlined in the Table 1 and - Fig. 1.

In the colonoscopy group, the reason for the MET calls was oxygen desaturation $(<90 \%)$ in one patient whereas in the rest of the patients $(n=4)$, the reason was transient hypotension with a recorded systolic blood pressure of $<90 \mathrm{mmHg}$ systolic, which resolved with IV fluid.

All the MET calls after gastroscopy were related to oxygen desaturation (oxygen saturation range $51 \%$ to $86 \%$ ). In seven cases, mask ventilation and subsequent endotracheal intubation were performed and the patients were then transferred to the intensive care unit. The gastroscopy indications in the MET call group requiring intubation were acute gastrointestinal bleeding $(n=6$; four variceal bleeding, two due to peptic ulcer disease) and one related to PEG tube insertion. Two of the intubated patients died after periods of 8 and 12 days, respectively. The other five patients who underwent endotracheal intubation recovered completely.

Each of the deaths occurred after an upper endoscopic procedure. One patient was a 57-year-old man with a history of alcoholism

\begin{tabular}{ll}
\hline Table 1 Demographic details of MET call patients. \\
No. patients \\
\hline Gender & $\begin{array}{l}\text { 20 males } \\
\text { 3 females }\end{array}$ \\
\hline Patient status & 15 inpatients \\
& 8 outpatients \\
\hline Mean age & 61.6 yr (range $28-84)$ \\
\hline ASA score - & 1 not recorded \\
II & 5 \\
III & 15 \\
IV & 2 \\
\hline Procedure indications & 12 upper gastrointestinal bleeding \\
Upper endoscopy & $(8$ variceal; 4 non-variceal) \\
& 1 PEG insertion \\
& 5 dysphagia \\
\hline Colonoscopy & 3 rectal bleeding \\
\end{tabular}

ASA, American Society of Anesthesiologists; yr, year; PEG, percutaneous endoscopic gastrostomy

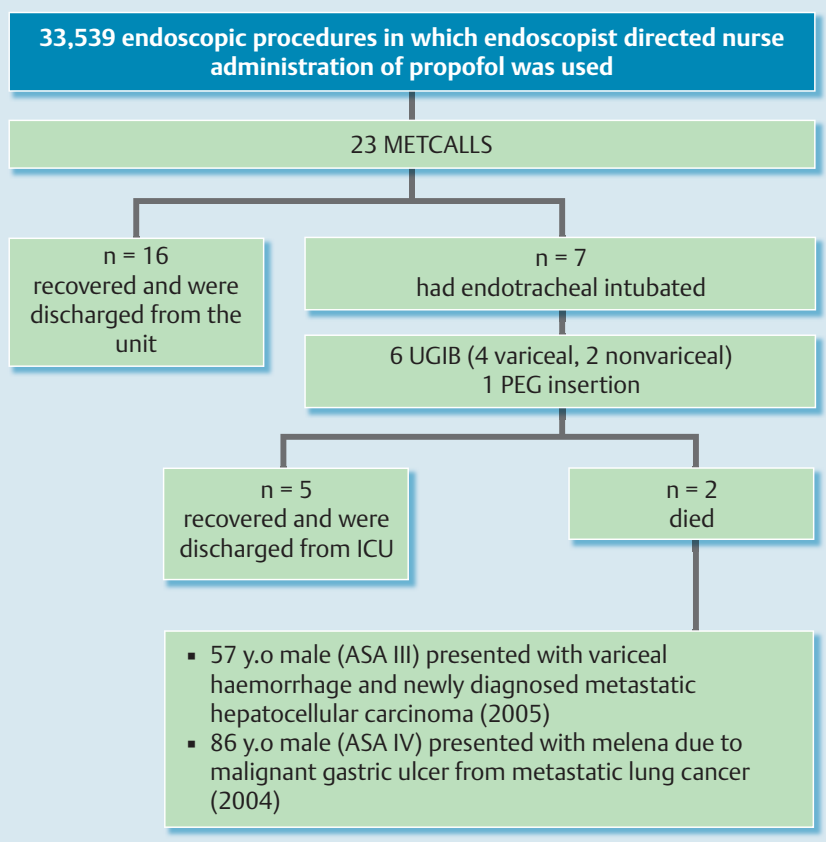

Fig. 1 Diagram illustrating the clinical outcome of the MET Call cases.

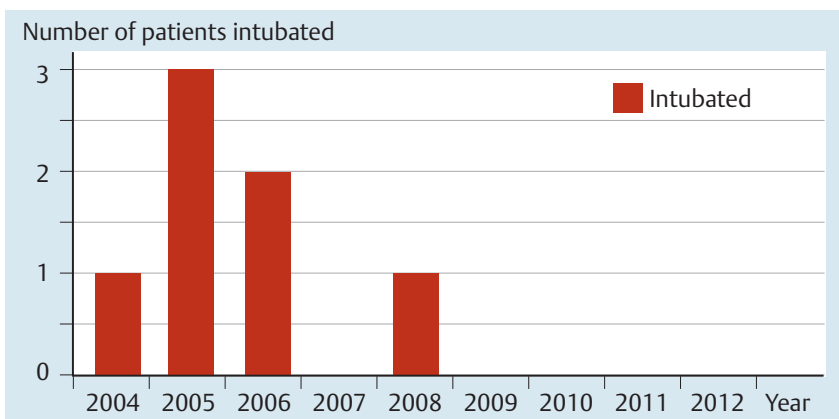

Fig. 2 Number of patients intubated.

and polysubstance abuse who presented to the Emergency Department in 2005 with acute gastrointestinal bleeding. His ASA score was III and he underwent urgent upper endoscopy with midazolam, fentanyl, and propofol sedation and was found to 
have bleeding esophageal varices. He underwent successful variceal banding but became cyanotic shortly after the procedure was completed. He was mask ventilated and then intubated. There was no evidence of aspiration, and his chest $\mathrm{x}$-ray remained clear. However, he subsequently developed decompensated liver disease with ascites and imaging revealed multiple liver lesions, which were consistent with hepatocellular cancer lesions on computed tomography scan. Palliative care was instituted and the patient died 8 days after presentation. The second patient who died was an 86-year-old man with an ASA score of IV who presented with melena in 2004. He underwent successful upper endoscopy with a combination of midazolam, fentanyl, and propofol, which revealed a large gastric ulcer in the body of the stomach. In the recovery area, he awoke from sedation but subsequently developed shortness of breath and hypoxemia. He was successfully resuscitated, intubated, and ventilated. There was no evidence of aspiration. His gastric biopsies subsequently revealed adenocarcinoma and further imaging revealed metastatic lung cancer. He died 12 days after presentation. In both of these cases, we believe the deaths were unrelated to administration of EDNAPS per se.

Analysis of the need for tracheal intubation over the 9-year period of the study showed that there was no requirement for endotracheal intubation since 2008 ( $\bullet$ Fig. 2).

\section{Discussion}

$\nabla$

This report confirms the good safety record of EDNAPS. More than 30000 patients were sedated using EDNAPS with minimal major morbidity or mortality. EDNAPS has been shown to be safe in ambulatory care settings. This study has shown that it is also safe in a tertiary referral center, in which there are more urgent and semi-urgent cases and in which endoscopists are trained. The deaths in this series occurred in emergency cases of moderate to high risk and patient factors clearly were contributory. It is acknowledged that the ASA III and IV cases that led to MET calls in this series should not have been performed using EDNAPs. In this regard, it is also noteworthy that during the last 4 years of the study, emergency endotracheal intubation was not required for any patient following EDNAPS including those who received MET calls. We speculate that the safety of EDNAPS for upper endoscopic procedures may have improved over the years due to better patient selection and ongoing improvements in nursing training and accreditation. Were the two patients who subsequently died in this series to be treated today, given our stricter exclusion criteria and the greater experience of our attending nursing and medical staff, they would be sedated by specialist anesthetists. Nevertheless, given these patients' advanced coexistent malignancies, it is doubtful whether anesthetic assistance would have significantly prolonged their lives [3]. There is also no evidence that resuscitation efforts in these patients were delayed or ineffective. Clearly, patient selection is critical if sedation-related complications are to be avoided.

Our results also confirm previous findings that the risk of complications during EDNAPS is greater during upper endoscopic procedures than during colonoscopy. Indeed, to our knowledge, there is still not a single report of death in the literature attributable to EDNAPS for colonoscopy. The reasons why sedationrelated complications and ventilatory support are needed more often during upper endoscopy are unclear. Possible explanations include a deeper average level of sedation and a higher incidence of coughing and laryngospasm during upper endoscopy. In addition, the occupation of the upper aerodigestive tract by the endoscope may make airway support more challenging in these patients. In this regard, in one small study, to overcome this problem, a mask adaptor was used instead of traditional mask ventilation to provide positive pressure ventilation during upper gastrointestinal endoscopy [41]. The potential applicability of such a device in EDNAPS is unclear, although it may have a role in nonurgent patients at higher risk of apnea.

It is important to be cognizant of the limitations of EDNAPS. In particular, it is inappropriate to perform endoscopy on high-risk patients with EDNAPS. At Canberra Hospital, there are designated lists for endoscopic procedures to be performed in the endoscopy unit with anesthetic assistance. It is also compulsory that all ERCPs be undertaken with the assistance of specialist anesthetists. Finally, there is also provision for performance of upper gastrointestinal endoscopy in the operating room in patients who are seriously ill and potentially unstable, such as those presenting with substantial variceal bleeding. Only with careful patient selection and ongoing quality assurance can sedation-related morbidity and mortality be minimized and the appropriate role for EDNAPS be defined.

Other limitations of this study include the possibility that some endoscopic procedures performed in the endoscopic unit may not have been recorded in the standardized reporting system. That, however, was minimized by the requirement that each patient have a typed, computer-generated report before departing the endoscopy suite. Secondly, there may have been episodes of physiological deterioration that did not trigger a MET call but which may have led to medium- or long-term morbidity. That, too, is unlikely because the MET team in our institution is very accessible and can be summoned with the push of a button. Nonetheless, it is acknowledged that details of transient sedation-induced physiological changes were not captured by the methodology employed in this study. Finally, the applicability of the results of this study to other tertiary referral centers may be limited to the extent that higher-risk patients and those undergoing more complex procedures such as ERCP were excluded.

Anesthetist-administered propofol for routine procedures in average-risk patients is costly [3]. In addition, there are not enough specialist anesthetists to provide sedation services for the rapidly rising number of endoscopic procedures being performed in developed countries. A previous

meta-analysis, albeit pertaining to endoscopic procedures performed predominantly in a community setting, has shown that anesthetic support is not cost-effective [3]. Our results confirm that propofol can be administered safely by trained registered nurses. The Australian and New Zealand College of Anaesthetists has recognized that propofol may be safely administered by nonanesthetists and, in conjunction with the Gastroenterological Society of Australia and the Royal Australasian College of Surgeons, this tripartite group has promulgated an important set of guidelines in this regard, which have been updated subsequent to the current study $[6,43]$. We believe that use of EDNAPS is likely to expand and it has certainly been widely reported in the United States, Canada, Switzerland, and European Union countries [38$40,42]$. This study shows that the potential role of EDNAPS in tertiary referral centers and teaching hospitals is substantial.

\section{Competing interests: None}




\section{References}

1 Clarke A, Chiragakis L, Hillman LC et al. Sedation for endoscopy: the safe use of propofol by general practitioner sedationists. Med J Aust 2002; 176: $158-161$

2 Thomson A, Andrew G, Jones DB. Optimal sedation for gastrointestinal endoscopy: review and recommendations. J Gastroenterol Hepatol 2010; 25: 469-478

3 Rex DK, Deenadayalu VP, Eid E et al. Endoscopist-directed administration of propofol: a worldwide safety experience. Gastroenterology 2009 Oct137: $1229-1237$

4 Vargo JJ, Zuccaro G, Dumot JA et al. Gastroenterologist-administered propofol versus meperidine and midazolam for advanced upper endoscopy: a prospective, randomized trial. Gastroenterology 2002; 123: $8-16$

5 Bell GD, Charlton JE. Colonoscopy - is sedation necessary and is there any role for intravenous propofol? [Editorial] Endoscopy 2000; 32: 264-267

6 Australian and New Zealand College of Anaesthetists and Gastroenterological Society of Australia. Sedation for endoscopy. Melbourne: ANZCA; 1997

7 Kulling $D$, Orlandi $M$, Inauen $W$. Propofol sedation during endoscopic procedures: how much staff and monitoring are necessary? Gastrointest Endosc 2007; 66: $443-449$

8 Rex DK, Heuss LT, Walker JA et al. Trained registered nurses/endoscopy teams can administer propofol safely for endoscopy. Gastroenterology 2005; 129: $1384-1391$

9 Kongkam P, Pornphisarn B, Rerknimitr R. Non-anaesthetist administered propofol for ERCP; efficacy, safety profile and side effect: a prospective randomized trial [abstract]. Gastrointest Endosc 2004; 59: AB127

10 Gonzalez-Huix F, Aldeguer X, Fort $E$ et al. Sedation without anaesthesiologist in 5250 endoscopic procedures: midazolam vs. midazolam vs. propofol [abstract]. Gastrointest Endosc 2004; 59: AB133

11 Kulling $D$, Rothenbuhler $R$, Inauen $W$. Safety of nonanesthetist sedation with propofol for outpatient colonoscopy and esophagogastroduodenoscopy. Endoscopy 2003; 35: 679-682

12 Cohen $L B$, Hightower $C D$, Wood $D A$ et al. Moderate level sedation during endoscopy: a prospective study using low-dose propofol, meperidine, fentanyl, and midazolam. Gastrointest Endosc 2004; 59: 795-803

13 Heuss LT, Froehlich F, Beglinger C. Changing patterns of sedation and monitoring practice during endoscopy: results of a nationwide survey in Switzerland. Endoscopy 2005; 37: $161-166$

14 Vargo JJ, Holub JL, Faigel DO et al. Risk factors for cardiopulmonary events during propofol-mediated upper endoscopy and colonoscopy. Aliment Pharmacol Ther 2006; 24: 955-963

15 Koshy G, Nair S, Norkus E et al. Propofol versus midazolam and meperidine for conscious sedation in GI endoscopy. Am J Gastrenterol 2000; 95: $1476-1479$

16 Yusoff IF, Raymond G, Sahai AV. Endoscopist administered propofol for upper-GI EUS is safe and effective: a prospective study in 500 patients. Gastrointest Endosc 2004; 60: 356-360

17 Sinnott J, Fricker E, Rogers A. Propofol, meperidine versus midazolam, meperidine: a one year comparison in a community based surgery center. Am J Gastroenterol 2004; 99: 303-S304

18 Meah N, Parikh PB. Efficacy and safety of nurse-administered propofol as an adjunctive agent of conscious sedation in private non-academic gastroenterology practice setting. Am J Gastroenterol 2004; 99: S313

19 Riphaus A, Stergiou N, Wehrmann T. Sedation with propofol for routine ERCP in high-risk octogenarians: a randomized, controlled study. Am J Gastroenterol 2005; 100: 1957-1963

20 Chen WX, Lin HJ, Zhang WF et al. Sedation and safety of propofol for therapeutic endoscopic retrograde cholangiopancreatography. Hepatobiliary Pancreat Dis Int 2005; 4: 437-440

21 Tohda G, Higashi S, Wakahara $S$ et al. Propofol sedation during endoscopic procedures: safe and effective administration by registered nurses supervised by endoscopists. Endoscopy 2006; 38: 360 - 367

22 Cohen LB, Dubovsky AN, Aisenberg J et al. Propofol for endoscopic sedation: a protocol for safe and effective administration by the gastroenterologist. Gastrointest Endosc 2003; 58: 725 - 732
23 Wehrmann T, Grotkamp J, Stergiou N et al. Electroencephalogram monitoring facilitates sedation with propofol for routine ERCP: a randomized, controlled trial. Gastrointest Endosc 2002; 56: 817-824

24 Wehrmann T, Kokabpick S, Lembcke B et al. Efficacy and safety of intravenous propofol sedation during routine ERCP: a prospective, controlled study. Gastrointest Endosc 1999; 49: 677-683

25 Carlsson U, Grattidge P. Sedation for upper gastrointestinal endoscopy: a comparative study of propofol and midazolam. Endoscopy 1995; 27 : $240-243$

26 Saenz-Lopez S, Rodriguez Munoz S, Rodriguez-Alcalde D et al. Endoscopist controlled administration of propofol: an effective and safe method of sedation in endoscopic procedures. Rev Esp Enferm Dig 2006; 98: 25-35

27 Tohda G, Higashi S, Sakumoto H et al. Efficacy and safety of nurse-administered propofol sedation during emergency upper endoscopy for gastrointestinal bleeding: a prospective study. Endoscopy 2006; 38 : 684-689

28 Barbi E, Petaros P, Badina L et al. Deep sedation with propofol for upper gastrointestinal endoscopy in children, administered by specially trained paediatricians: a prospective case series with emphasis on side effects. Endoscopy 2006; 38: 368-375

29 Peter S, Wunderlich P, Beglinger $C$ et al. Is nurse administered propofol sedation (NAPS) safe for endoscopies in a gastroenterologist ambulatory practice? [abstract] Gastroenterology 2007; 132: A129

30 Sipe $B W$, Scheidler $M$, Baluyut $A$ et al. A prospective safety study of a low-dose propofol sedation protocol for colonoscopy. Clin Gastroenterol Hepatol 2007; 5: 563-566

31 Tagle M, Siu H, Ramos M. Propofol in combination with meperidine and midazolam in colonoscopy and upper endoscopy: first prospective study in private practice in Peru. Rev Gastroenterol Peru 2007; 27: $367-373$

32 Morse JW, Fowler SA, Morse AL. Endoscopist-administered propofol: a retrospective safety study. Can J Gastroenterol 2008; 22: 617-620

33 Vargo JJ. Propofol: a gastroenterologist's perspective. Gastrointest Endosc Clin North Am 2004; 14: 313-323

34 Sipe BW, Rex DK, Latinovich D et al. Propofol versus midazolam, meperidine for outpatient colonoscopy: administration by nurses supervised by endoscopists. Gastrointest Endosc 2002; 55: 815-825

35 Ulmer BJ, Hansen JJ, Overley CA et al. Propofol versus midazolam, fentanyl for outpatient colonoscopy: administration by nurses supervised by endoscopists. Clin Gastroenterol Hepatol 2003; 1: 425-432

36 Faulx AL, Vela S, Das A et al. A changing landscape of practice patterns regarding unsedated endoscopy and propofol use: a national survey [abstract]. Gastrointest Endosc 2004; 59: AB131

37 Dewitt J, Leblanc J, McHenry L et al. Registered nurse-administered propofol sedation (RNAPS) versus midazolam and meperidine (MM) for endoscopic ultrasound (EUS): a prospective, randomized trial [abstract]. Gastrointest Endosc 2003; 57: AB78

38 Byrne MF, Chiba N, Singh $H$ et al. Propofol use for sedation during endoscopy in adults: a Canadian Association of Gastroenterology position statement. Can J Gastroenterol 2008; 22: 457-459

39 American Society for Gastrointestinal Endoscopy. Training guideline for use of propofol in gastrointestinal endoscopy. Gastrointest Endosc 2004; 60: $167-172$

40 Cohen $L B$, Delegge MH, Aisenberg J et al. AGA institute review of endoscopic sedation. Gastroenterology 2007; 19: 397-404

41 Yongzi C, Xizhuo S et al. Mask adaptor - a novel method of positive pressure ventilation during propofol deep sedation for upper GI endoscopy. Gastrointestinal Endosc 2008: 68; $127-131$

42 Knape JT, Adriaensen $\mathrm{H}$, van Aken $\mathrm{H}$ et al. Guidelines for sedation and/or analgesia by non-anaesthesiology doctors. Eur J Anaesthesiol 2007; 24: $563-567$

43 Australian and New Zealand College of Anaesthetists Guidelines. http://www.anzca.edu.au/resources/professional-documents/pdfs/ ps09-2014-guidelines-on-sedation-and-or-analgesia-for-diagnosticand-interventional-medical-dental-or-surgical-procedures.pdf 